\title{
Targeting hypoxia in tumor: a new promising therapeutic strategy
}

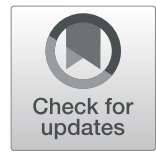

\author{
Maria Carla Bosco ${ }^{1}$, Gabriella D'Orazi ${ }^{2,3^{*}}$ (ID) and Donatella Del Bufalo ${ }^{4}$
}

\begin{abstract}
Low oxygen condition (hypoxia) is considered a hallmark of rapidly growing solid tumors. The presence of hypoxia renders tumor cells resistant to conventional chemo- and radio-therapy, selecting a more malignant and invasive phenotype and playing a negative role in patient prognosis. This commentary wishes to recognize the 2019 Nobel Prize in Medicine awarded to three physicians-scientists, Prof. William G. Kaelin Jr., Prof. Sir Peter J. Ratcliffe, and Prof. Gregg L. Semenza, for their discovery of the mechanisms mediating cell ability to sense and adapt to changes in oxygen availability. Their studies established the basis for our understanding of the role of hypoxia in a variety of diseases, including anemia, renal failure, cardiovascular disease, metabolic diseases, and cancer, paving the way for new promising therapeutic strategies through the development of drugs that can either activate or block the oxygen-sensing machinery.
\end{abstract}

Keywords: Hypoxia, HIF, Oxygen sensing, VHL, Angiogenesis, VEGF, Cancer, Metastasis

\section{Background}

The fundamental importance of adequate oxygenation for energy production has been recognized for centuries, but how cells and tissues are able to sense and adapt to changes in oxygen availability remained elusive until the late twentieth century. In the last 30 years, three physician-scientists, William G. Kaelin Jr., Sir Peter J. Ratcliffe, and Gregg L. Semenza, focused their studies on the molecular mechanisms of oxygen detection in human and animal cells and the signaling pathways and biological processes by which they respond to low oxygen level, referred to as hypoxia. Their work provided a series of closely overlapping and sometimes competitive contributions that ended with the Nobel Prize in Medicine 2019. In 1995, Semenza identified the Hypoxia Inducible Factor-1 (HIF-1) as a basic-helix-loop-helixPAS $\alpha / \beta$ heterodimeric transcription factor regulated by cellular oxygen tension [1]. Afterward, the three scientists independently identified different molecular

\footnotetext{
* Correspondence: gdorazi@unich.it

2Department of Medical Science, University "G. D'Annunzio", 66013 Chieti, Italy

${ }^{3}$ Unit of Cellular Networks and Molecular Therapeutic Targets, Department of Research and Advanced Technologies, IRCCS Regina Elena National Cancer Institute, 00144 Rome, Italy

Full list of author information is available at the end of the article
}

mechanisms through which cells regulate HIF-1 activity and the downstream induced genes, among which, erythropoietin (EPO) [1] and angiogenic factors [2], modulating about $5 \%$ of the human genome (Fig. 1a) and affecting many different diseases, as evidenced by the increased number of papers published on this topic in the last 25 years (Fig. 1b). HIF-1-dependent induction of hypoxia-responsive genes has been shown in hypoxic regions of tumor xenografts, suggesting a connection between HIF and cancer. Ratcliffe and Kaelin demonstrated the relevance of the von Hippel-Lindau (VHL) tumor suppressor protein for HIF-1 $\alpha$ degradation through oxygen-regulated prolyl hydroxylation [3, 4], and Semenza identified the factor inhibiting HIF-1 (FIH1 ) as a novel protein interacting with HIF-1 $\alpha$ and VHL gene to mediate repression of HIF-1 transcriptional activity [5]. Prolyl hydroxylation at specific sites of HIF- $1 \alpha$ is the crucial oxygen-dependent post-translational modification required for its recognition and degradation by the VHL ubiquitin proteasome pathway. This process is blocked under hypoxic conditions because oxygenrequiring HIF hydroxylases no longer act, and HIF-1 $\alpha$ can be stabilized and assembled with the HIF- $1 \beta$ dimerization partner, binding to the hypoxia response elements (HRE) of hypoxia-regulated genes and transactivating their expression [4] (Fig. 1a). Furthermore, regulation of HIF-1 

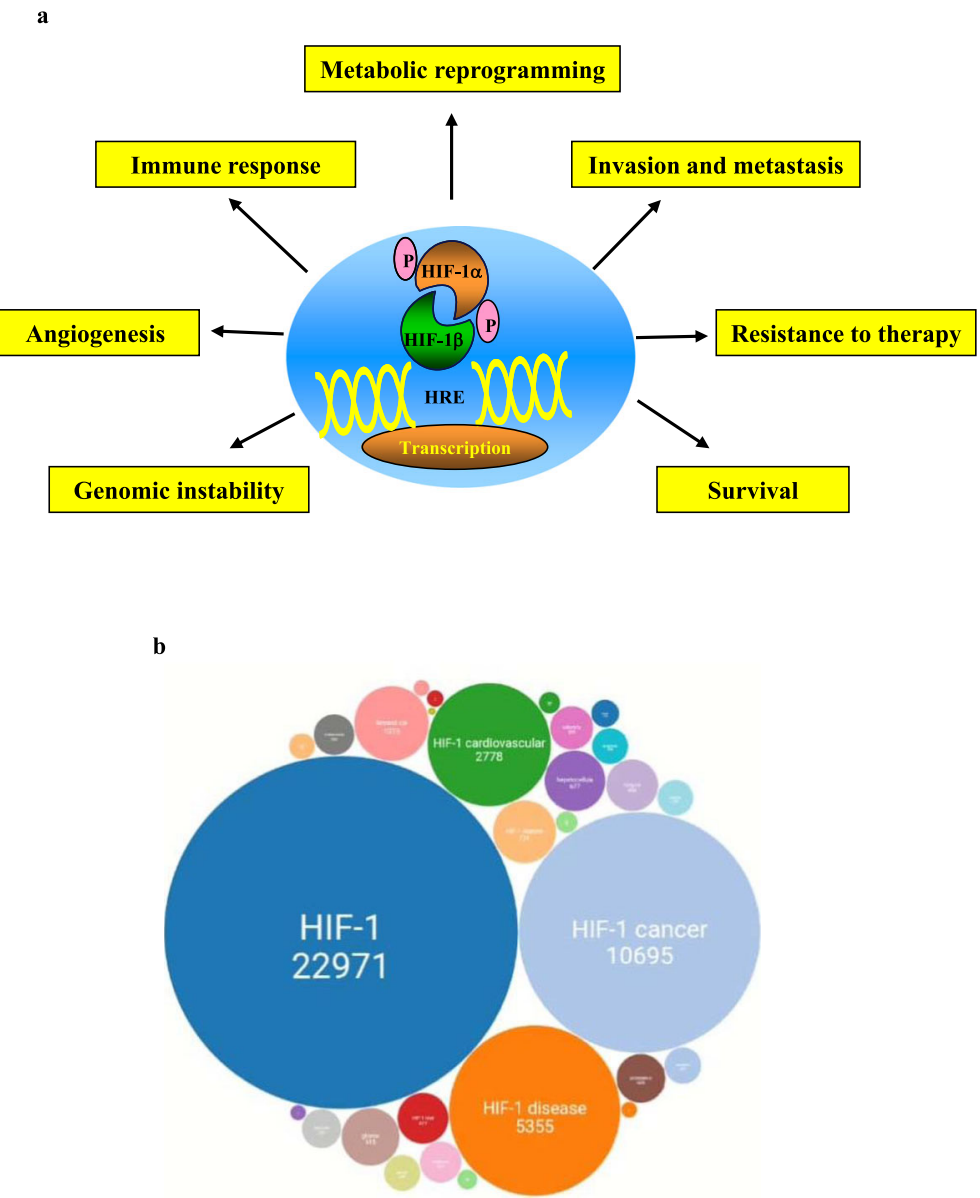

Fig. 1 Schematic representation of the effects of intratumoral hypoxia in human diseases. a Hypoxia-inducible factor 1 (HIF-1) is a heterodimeric protein that consists of a constitutively expressed HIF-1 $\beta$ subunit and a HIF-1a subunit regulated by $\mathrm{O}_{2}$-dependent mechanisms. Activated HIF-1 transcription factor binds to the hypoxia response elements (HRE) to induce transcription of, among others, target genes involved in angiogenesis, glucose metabolism, cell proliferation/survival, and invasion/metastasis. b Schematic representation of the number of scientific papers related to HIF-1, published in the last 25 years, and the relative diseases

activity has been shown to depend also on hypoxiaindependent genetic alteration [3-5]. Starting from these studies, a plethora of regulators of HIF-1 transcriptional activity and HIF target genes affecting cellular responses to oxygen availability and, in particular, to hypoxic conditions, have been identified by researchers from all over the world [6, 7]. In 2010 the three scientists shared the Canada Gairdner International Award and in 2016 they received the Albert Lasker Award for Basic Medical Research for their work on oxygen sensing.

HIF-1 plays important roles in critical aspects of cancer biology, including angiogenesis, regulation of glucose and energy metabolism, epithelial-to-mesenchymal transition, invasion, metastasis, and stem cell maintenance (Fig. 1a), thus allowing tumor cells to proliferate and survive under hypoxic conditions. These discoveries provided proof-of-principle that inhibition of HIF-1 activity may represent a novel strategy for the therapy not only of cancer but also for other diseases characterized by impaired oxygenation, such as anemia, coronary artery disease, obstructive pulmonary diseases, chronic ischemic cardiomyopathy, inflammatory synovitis, atherosclerosis, systemic sclerosis, etc. [8, 9].

Over the last two decades, to bridge basic science to the clinical situation, dozens of putative small molecule HIF inhibitors that directly or indirectly downregulate HIF- $1 \alpha$ have been identified and are currently tested in clinical trials for various forms of cancer [10]. Several HIF prolyl hydroxylase inhibitors, that prevent VHL from binding to HIF-1 $\alpha$, have also been developed and are now in late-stage clinical trials in disease in which HIF signaling is beneficial, e.g. to augment endogenous EPO production for the treatment of renal-based anemia. Such drugs are also being investigated for the treatment of circulatory diseases and for the protection against ischemic injury and inflammatory diseases, other than as anticancer molecules. 


\section{Conclusion}

Hypoxia is considered a driving force of tumor progression and a negative prognostic factor. The finding of HIF as the main regulator of transcriptional responses to changes in oxygen levels has far-reaching implications, opening up new avenues for the development of new promising therapeutic strategies targeting the HIFsignaling pathway. In this regard, Journal of Experimental \& Clinical Cancer Research is announcing a special issue to highlight significant advances in the understanding of the impact of hypoxia on tumor progression and treatment efficacy.

\section{Abbreviations}

EPO: Erythropoietin; FIH-1: Factor inhibiting HIF-1; HIF-1: Hypoxia Inducible Factor-1; HRE: Hypoxia response elements; VHL: Von Hippel-Lindau

\section{Acknowledgements}

We thank all the people in the lab for critical discussion.

\section{Authors' contribution}

All authors were involved in conceptualization, writing and revising the manuscript. All authors read and approved the final version of the manuscript.

\section{Funding}

The research within the realm of this manuscript is funded in G.D. lab by the Associazione Italiana per la Ricerca sul Cancro (AIRC) (IG 2015 16742) and by Fondi Ateneo; in M.C.B. lab by Ministry of Health (Ricerca Finalizzata RF-201602361048) and by AIRC (IG 2015 17459); in D.D.B. lab by AIRC (IG 2016 18560).

Availability of data and materials

Not applicable.

Ethics approval and consent to participate

Not applicable.

\section{Consent for publication}

Not applicable.

\section{Competing interests}

The authors declare that they have no competing interests.

\section{Author details}

${ }^{1}$ Laboratory of Molecular Biology, IRCCS Istituto Giannina Gaslini, 16147 Genova, Italy. "Department of Medical Science, University "G. D'Annunzio", 66013 Chieti, Italy. ${ }^{3}$ Unit of Cellular Networks and Molecular Therapeutic Targets, Department of Research and Advanced Technologies, IRCCS Regina Elena National Cancer Institute, 00144 Rome, Italy. ${ }^{4}$ Preclinical Models and New Therapeutic Agents Unit, Department of Research and Advanced Technologies, IRCCS Regina Elena National Cancer Institute, 00144 Rome, taly.

Received: 6 December 2019 Accepted: 23 December 2019

Published online: 10 January 2020

\section{References}

1. Wang $G L$, Jiang BH, Rue EA, Semenza GL. Hypoxia-inducible factor 1 is a basic-helix-loop-helix-PAS heterodimer regulated by cellular $\mathrm{O} 2$ tension. Proc Natl Acad Sci U S A. 1995;92:5510-4.

2. Gleadle JM, Ebert BL, Firth JD, Ratcliffe PJ. Regulation of angiogenic growth factor expression by hypoxia, transition metals, and chelating agents. Am J Phys. 1995;268:C1362-8.

3. Ivan M, Kondo K, Yang H, Kim W, Valiando J, Ohh M, et al. HIF-1alpha targeted for $\mathrm{VHL}$-mediated destructionby proline hydeoxylation: implications for O2 sensing. Science. 2001;292:464-8.
4. Jaakkola P, Mole DR, Tiam YM, Wilson MI, Gielbert J, Gaskell SJ, et al. Targeting of HIF-alpha to the von Hippel-Lindau ubiquitylation complex by O2-regulated prolyl hydroxylation. Science. 2001;292:468-72.

5. Mahon PC, Hirota K, Semenza GL. FIH-1: a novel protein that interacts with HIF-1alpha and VHL to mediate repression of HIF-1 transcriptional activity. Genes Dev. 2001;15:2675-86.

6. Nardinocchi L, Puca R, Guidolin D, Belloni AS, Bossi G, Michiels C, et al. Transcriptional regulation of hypoxia-inducible factor 1alpha by HIPK2 suggests a novel mechanism to restrain tumor growth. Biochim Biophys Acta. 2009;1793:368-77.

7. Trisciuoglio D, Gabellini C, Desideri M, Ragazzoni Y, De Luca T, Ziparo E, et al. Involvement of $\mathrm{BH} 4$ domain of bcl-2 in regulation of HIF-1-mediated expression of hypoxic tumor cells. Cell Death Differ. 2011;18:1024-35.

8. Semenza GL. Oxygen sensing, homeostasis, and disease. New Engl J Med. 2011:365:537-47.

9. Bosco MC, Delfino S, Ferlito F, Battaglia F, Puppo M, Gregorio A, et al. Hypoxic synovial environment and expression of macrophage inflammatory protein 3gamma/CCL20 in juvenile idiopathic arthritis. Arthritis Rheum. 2008:58:1833-8.

10. Semenza GL. HIF-1 inhibitors for cancer therapy: from gene expression to drug discovery. Curr Pharm Des. 2009;15:3839-43.

\section{Publisher's Note}

Springer Nature remains neutral with regard to jurisdictional claims in published maps and institutional affiliations.
Ready to submit your research? Choose BMC and benefit from:
- fast, convenient online submission
- thorough peer review by experienced researchers in your field
- rapid publication on acceptance
- support for research data, including large and complex data types
- gold Open Access which fosters wider collaboration and increased citations
- maximum visibility for your research: over $100 \mathrm{M}$ website views per year
At BMC, research is always in progress.
Learn more biomedcentral.com/submissions 